\title{
Using effect size to quantify plantar pressure asymmetry of gait of nondisabled adults and patients with hemiparesis
}

\author{
François J. Potdevin, MD; ${ }^{1-2}$ Virginie G. Femery, PhD; ${ }^{1}$ Aurélien Decatoire, MD; ${ }^{1}$ Laurent Bosquet, PhD; $^{1}$ \\ Yann Coello, PhD; ${ }^{2}$ Pierre Moretto, PhD $^{\mathbf{1}^{*}}$ \\ ${ }^{1}$ Laboratoire d'Etudes de la Motricité Humaine, Faculté des Sciences du Sport et de l'Education Physique, Ronchin, \\ France; ${ }^{2}$ Unité de Recherche sur l'Evolution des Comportements et des Apprentissages, Université Charles de Gaulle, \\ Villeneuve d'Ascq cedex, France
}

\begin{abstract}
In the literature, numerous statistical analyses are used to quantify asymmetry in gait. This study tested the effect size (ES) statistic for quantifying asymmetry in nondisabled and pathological populations. The plantar pressure peaks on eight footprint locations of 27 nondisabled subjects and 18 patients with hemiparesis were bilaterally compared. Asymmetry quantifications were performed with ES and standard statistical tests (index of asymmetry, symmetry index, and ratio index). The results show an advantage in using ES to quantify asymmetry when confidence limits are also calculated. Conversely, traditional asymmetry indexes immediately implied asymmetry without statistical basis. These findings should be considered when one is attempting to diagnose pathological walking patterns or guide rehabilitation processes.
\end{abstract}

Key words: abnormality, baropodometric, diagnostic, normality, plantar pressure, quantification, rehabilitation, statistics, symmetry, walking.

\section{INTRODUCTION}

The way asymmetry in gait is detected and quantified is essential for differentiating a normal and a pathological gait [1] or discussing the different functions performed by the lower limbs during walking [2]. Gait asymmetry is assumed when statistical differences are noted between parameters recorded on the two limbs [3-4]. However, the classical matched-pairs tests indicate only the probability that the differences are real and that they did not occur by chance. These tests do not provide a measurement of the magnitude of these differences [5]. Similarly, the principal component analysis only allows different task priorities for each limb to be highlighted without any quantification differences between the limbs [2]. Nevertheless, asymmetry quantification is necessary for detecting limits between normality and abnormality in diagnosing pathological walking patterns or guiding rehabilitation processes [6].

Indexes have often been used for measuring the magnitude of bilateral differences [7-9], such as the difference either against their average value [1,8] or against the maximum bilateral value [9]. The higher the difference from 0 , the higher the asymmetry between the bilateral parameters. The major drawback of these measurements concerns positive or negative results that depend on the asymmetric side. For example, indexes of a group of

\footnotetext{
Abbreviations: $\mathrm{ES}$ = effect size, IA = index of asymmetry, ICC = intraclass correlation coefficient, $\mathrm{LH}=$ lateral heel, $\mathrm{LM}=$ lateral midfoot, $\mathrm{M}=$ metatarsal (heads 1-5), $\mathrm{MH}=$ medial heel, $\mathrm{MM}=$ medial midfoot, $\mathrm{PPP}=$ peak plantar pressure, $\mathrm{RI}=$ ratio index, $\mathrm{SD}=$ standard deviation, $\mathrm{SI}=$ symmetry index.

* Address all correspondence to Pierre Moretto, PhD; Laboratoire d'Etudes de la Motricité Humaine, Faculté des Sciences du Sport et de l'Education Physique, 9 rue de l'Université 59790, Ronchin, France; +33-03-20-88-73-76; fax: +33-03-20-88-73-63. Email: pierre.moretto@univ-lille2.fr DOI: 10.1682/JRRD.2006.07.0077
} 
patients having marked asymmetry — but half are on one side and the other half on the other side-would result in a mean value of 0 , thus suggesting symmetry in the gait pattern. On one hand, a mean index value far from 0 allows us to consider large asymmetry and indicate which side generally displays asymmetry. On the other hand, a mean index value near 0 is not a trustworthy indicator of symmetric behavior. A ratio index (RI) has also been used to quantify asymmetry. With this method, the value for a given gait parameter obtained from the right limb is divided by the associated value of the left limb [10-12]. A ratio of 1 indicates a reciprocal gait pattern, while higher or lower values reflect asymmetries. This method's drawback is that it, again, depends on the asymmetric side. That is, mean RI values distant from 1 may indicate asymmetrical behavior while mean values near 1 do not necessarily imply symmetrical behavior of the lower limbs.

All methods for measuring bilateral differences based on traditional asymmetry indexes imply asymmetric behavior [1], and the distinctions between a small and large difference are arbitrarily fixed. Clinicians and researchers looking at gait pathologies have overcome the limitations of traditional asymmetry indexes using an impaired versus a less-impaired limb classification [1315]. During walking and in nondisabled gait, the hypotheses of motor dominance [16-22] or functional asymmetry $[4,23]$ must be considered for one to eliminate the possibility of similar confounding effects. Femery et al. showed the relevance of the propulsive versus the cushioning limb classification for nondisabled and populations with hemiparesis in the study of asymmetry [14]. In this study, the dynamic peak plantar pressure (PPP) distribution over consecutive steps was compared bilaterally according to the classification described earlier. Asymmetry results were discussed in relation to functional strategies (propulsive vs cushion limb) rather than structural differences between the two limbs only. Femery et al. concluded that this classification was relevant for detecting limb function to guide rehabilitation processes or for evaluating the consequences of a possible surgical intervention [14].

The study of plantar pressure asymmetry must quantify bilateral differences statistically to discriminate between a normal and a pathological gait. Statistical limits are necessary for one to determine the magnitude of the difference. However, the calculation of percentage (symmetry index [SI], index of asymmetry [IA], and RI) may be a function of the sample size and variance of bilateral differences [24] and does not allow for decisions about pathological or normal gait patterns. For instance, Herzog et al. studied asymmetry in normal gait by comparing 34 gait parameters bilaterally [1]. They used the SI to quantify the bilateral difference. The upper and lower limits were found to vary from 4 to 13,000 percent. The lack of standardization of the difference does not allow for decisions about the clinical significance of the difference and so the limits between normal and high asymmetry are difficult to detect.

The effect size (ES) statistic is a method for determining the magnitude of the differences in the measure of the standardized effect. Indeed, ES values are a normalization of differences in the standard deviation (SD) values (mean difference expressed as a pooled SD), making it a standardized and more accurate description of the asymmetry. According to Rhea, ES is beneficial because it represents differences in SD units and allows differential comparison of the magnitudes in different but related studies [24]. Cohen proposed statistical limits to differentiate between small, moderate, and large differences [25]. While this method is currently used in the behavioral and social sciences, to our knowledge, it has never been used in the study of gait asymmetry in health or pathological populations. Therefore, the aim of our study was to test ES as applied to plantar pressure asymmetry. Comparisons between subjects who have marked gait asymmetries (patients with hemiparesis) with subjects who appear to have "normal" gait patterns (nondisabled young adults) are performed.

\section{METHODS}

\section{Subjects}

Our study included 31 nondisabled young adults (14 males and 17 females) and 18 patients with hemiparesis (13 males and 5 females) who all provided written informed consent in accordance with the protocol approved by an institutional review board. The mean age \pm SD of the data on the nondisabled group was $21.8 \pm 2.3$, height $171.9 \pm 8.0 \mathrm{~cm}$, and mass $65.2 \pm 10.9 \mathrm{~kg}$. Nondisabled subjects who had a physical abnormality (e.g., pes planus, pes cavus, or Morton's feet), been injured, or undergone surgery on a leg or foot during the past two years were not enrolled. The mean age \pm SD data on the group with hemiparesis was $16.6 \pm 2.7$, height $162.7 \pm$ $11.2 \mathrm{~cm}$, and mass $52.5 \pm 8.2 \mathrm{~kg}$. A clinical examination 
allowed us to select patients without any associated problems that could influence their gait (e.g., athetosis, mental deficiency, or severe visual problems). Severe sensory deficiencies were absent in all patients. One examiner assessed the spasticity of all subjects using passive mobilization of the leg. The reflex contraction of the stretched muscle was assessed by the Ashworth method. The spasticity score was evaluated for the quadriceps, the rectus femoris, and the triceps surae. All subjects with hemiparesis had minor spasticity, with spasticity scores between 1 and 2. We tested muscular function of the ankle to assess foot flexibility. All subjects could perform movements against an average resistance or gravity. The resistance was exerted by the examiner on the back of the foot for dorsi flexion and under the foot for plantar flexion. Every patient was subjected to podoscopy examination for identification of foot shape. All subjects were diagnosed with either a normal foot shape or a minor arched foot. All subjects had to be able to walk $30 \mathrm{~m}$ independently and without a walking device.

\section{Data Collection}

All subjects were tested during overground locomotion at their preferred speed over a distance of $20 \mathrm{~m}$ for the nondisabled subjects and $12 \mathrm{~m}$ for the patients with hemiparesis. Time spent covering the distance was measured, from which spontaneous velocity was calculated. Spontaneous velocity was imposed because asymmetry increases when gait velocity is 10 percent lower than spontaneous velocity [26].

We recorded PPP with a Parotec in-shoe pressure measurement system (Paromed GmbH, D-8201, Markt Neubeuern, Germany) over eight consecutive steps to leave the natural walking pattern undisturbed. The system consisted of two insoles and a data acquisition box carried on a belt with the sampling rate set at $250 \mathrm{hz}$. Each insole contained 16 microsensors mounted within a constrained hydrocell (Figure). A detailed description of this measuring system has been reported elsewhere [13], and the accuracy and sensor distribution of the Parotec insoles have been validated by several studies [14,27-29]. The 16 hydrocell sensors were grouped by size and shape to describe eight footprint locations: lateral heel $(\mathrm{LH})$ and medial heel (MH), lateral midfoot (LM) and medial midfoot (MM), fourth to fifth (M4-5), second to third (M2-3), and first (M1) metatarsal heads, and the hallux.

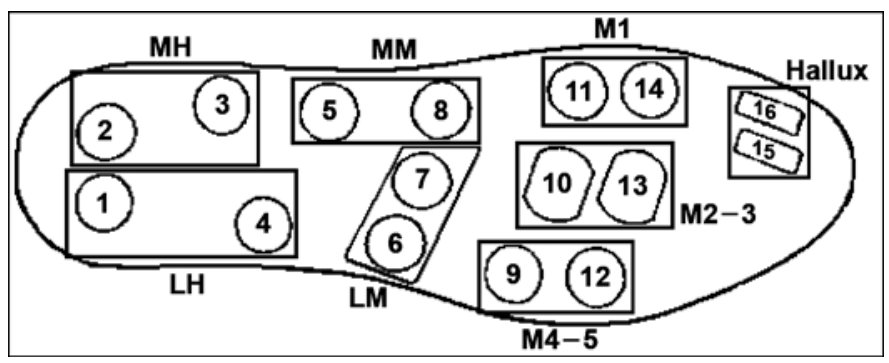

Figure.

Sensor distribution with Parotec insoles (Paromed GmbH, D-8201, Markt Neubeuern, Germany). LH = lateral heel, LM = lateral midfoot, $\mathrm{MH}=$ medial heel, $\mathrm{MM}=$ medial midfoot, $\mathrm{M} 1=1 \mathrm{st}$ metatarsal head, M2-3 = 2nd to 3rd metatarsal head, M4-5 = 4th to 5th metatarsal head.

\section{Data Classification}

For the nondisabled group, we identified each lower limb by a propulsive versus a cushioning classification according to the methodology of Femery et al. [14]. These authors showed that the lower limb with the lowest peak vertical force values under the rear foot (cushion function) was different from the lower limb with the highest peak vertical force values under the forefoot (propulsion function). We calculated the sum of PPP values under the heel $(\mathrm{LH}+\mathrm{MH})$ to determine the cushioned lower limb. The cushioned lower limb was referred to as the minimum sum of PPP values under $\mathrm{LH}$ and $\mathrm{MH}$. The propulsive leg was referred to as the maximum sum of PPP values under $\mathrm{LH}$ and $\mathrm{MH}$. We categorized the limbs of the group with hemiparesis using an affected versus unaffected classification.

\section{Statistical Analysis}

Normal Gaussian distribution and homoscedasticity (homogeneity of the variances) of the data were tested by the Shapiro-Wilk's and Levenne tests, respectively. Reliability of the data across the consecutive steps for each limb was tested with the use of the intraclass correlation coefficient (ICC) according to the recommendations of Schrout and Fleiss [30]. The statistical analyses were applied to the means of the eight steps for each subject.

When normality and homoscedasticity assumptions were met, the student's $t$-test for paired data was performed on the bilateral values for the same footprint locations. Otherwise, the Wilcoxon matched-pairs test was used. Because the aim of our study was to test a method to quantify asymmetry, we fixed $p$-values at $0.05,0.01$, and 0.001 . We determined the SI proposed by Robinson et al. [8], the IA defined by Vagenas and Hoshizaki [9], 
and the RI used by several authors [9-11] to quantify the bilateral differences. The equations are

$$
\begin{aligned}
\mathrm{SI} & =\frac{\overline{\mathrm{PPP}_{1}}-\overline{\mathrm{PPP}_{2}}}{0.5\left(\mathrm{PPP}_{1}+\mathrm{PPP}_{2}\right)} \times 100, \\
\mathrm{IA} & =\frac{\overline{\mathrm{PPP}_{1}}-\overline{\mathrm{PPP}_{2}}}{{\mathrm{Max}\left(\mathrm{PPP}_{1} ; \mathrm{PPP}_{2}\right)}_{100, \text { and }}} \\
\mathrm{RI} & =\frac{\overline{\mathrm{PPP}_{1}}}{\mathrm{PPP}_{2}},
\end{aligned}
$$

where $\mathrm{PPP}_{1}=$ peak plantar pressure for the unaffected side within the group with hemiparesis and for the cushion side within the nondisabled group and $\mathrm{PPP}_{2}=$ peak pressure for the affected side within the group with hemiparesis and for the propulsive side within the nondisabled group.

For each statistical procedure, we applied the ES statistic to quantify the magnitude of the bilateral difference in PPP values according to the recommendations of several authors [5,25,31]. The ES equation is

$$
E S=\frac{\left(\overline{\mathrm{PPP}_{1}}-\overline{\mathrm{PPP}_{2}}\right)}{\sqrt{\frac{\sigma^{2} \mathrm{PPP}_{1}+\sigma^{2} \mathrm{PPP}_{2}}{2}}},
$$

where $\sigma=\mathrm{SD}$. ES is used for comparing treatment effects independent of sample size. Cohen indicated that absolute ES size values of $<0.2$ represent small treatment differences, $\sim 0.5$ represent moderate treatment differences, and $>0.8$ represent large treatment differences [25]. Spearman correlations between values of ES, SI, IA, and RI for the eight areas were applied for the two groups. Absolute values of ES, SI, IA, and RI for the eight areas were compared between the two groups with the Wilcoxon matched-pairs test.

\section{RESULTS}

\section{Nondisabled Group}

Mean PPP values and SDs calculated from the eight steps of each subject in the nondisabled group are presented in Table 1. Normality of the data was verified for all footprint areas $(p>0.05)$ apart from LM (propulsive side), MM (propulsive side), and M2-3 (cushion side). Homoscedasticity was met for all footprint areas ( $p>$ $0.05)$. ICC averaged values for all areas were $0.83 \pm 0.12$ for the cushioned side and $0.80 \pm 0.19$ for the propulsive side. Mean spontaneous velocity was $1.16 \pm 0.06 \mathrm{~m} \cdot \mathrm{s}^{-1}$. Cushioned and propulsive PPP values under LH and MH were significantly different $(p<0.05)$. Moderate differences were identified with ES for the MM area $(-0.40)$. Small differences were shown for the $\mathrm{MH}, \mathrm{LH}$, and hallux areas $(-0.36,-0.26$, and -0.24 , respectively). SI values furthest from 0 were calculated under the MM $(30.8 \pm$ 101.5\%), hallux (-10.4 $\pm 31 \%)$, $\mathrm{MH}(-7.3 \pm 13.5 \%)$, and LH $(-5.3 \pm 11.8 \%)$ areas. IA values furthest from 0 were calculated under the MM (17.1 $\pm 58.4 \%)$, hallux $(-8.9 \pm$ $24.8 \%)$, MH (-6.6 $\pm 12.1 \%)$, and LH (-4.7 $\pm 11.5 \%)$ areas. RI values furthest from 1 were calculated under the MM (2.09 \pm 2.89$)$, LM (1.13 \pm 0.69$)$, M1 (1.11 \pm 0.45$)$, and M4-5 (1.09 \pm 0.46$)$ areas. Correlation coefficient values were significant for ES, SI, and IA $\left(p<0.01, R^{2}=\right.$ $0.81)$; for ES and RI ( $\left.p<0.05, R^{2}=0.67\right)$; and for SI, IA and RI $\left(p<0.05, R^{2}=0.57\right)$ (Table 2).

\section{Group with Hemiparesis}

Mean PPP values and SDs calculated from the eight steps of each subject in the group with hemiparesis are also presented in Table 1. Normality of the data was met for all footprint areas ( $p>0.05)$ apart from MM (affected and unaffected sides), M2-3 (unaffected side), and hallux (unaffected and affected sides). Homoscedasticity was verified for all footprint areas $(p>0.05)$ apart from MM, M2-3, and hallux areas. ICC averaged values for all areas were $0.41 \pm 0.15$ for the unaffected limb and $0.43 \pm$ 0.15 for the affected limb. Mean spontaneous velocity was significantly lower for this group than for the nondisabled group $\left(0.97 \pm 0.09 \mathrm{~m} \cdot \mathrm{s}^{-1}\right.$ vs $\left.1.16 \pm 0.06 \mathrm{~m} \cdot \mathrm{s}^{-1}, p<0.01\right)$. Impaired and less-impaired PPP values under $\mathrm{LH}, \mathrm{MH}$, MM, M4-5, and M1 were significantly different $(p<0.05$ and $p<0.01$ for MM). We identified large differences using ES for the MM (-1.13), LH (0.96), and M4-5 (0.84) areas. Moderate differences were found for the $\mathrm{MH}, \mathrm{M} 1$, and hallux areas $(0.74,-0.61$, and 0.42 , respectively). Small differences were shown for M2-3 (ES = 0.35). SI values furthest from 0 were calculated under the MM $(82.3 \pm 82.1 \%)$, LH $(-43.5 \pm 73.0 \%)$, hallux $(-40.6 \pm$ 109.8\%), MH (-32.6 \pm 58.6\%), M4-5 (-31.8 $\pm 46.7 \%)$, and M2-3 $(-13.5 \pm 40.5 \%)$ areas. IA values furthest from 0 were calculated under the MM $(49.0 \pm 49.8 \%)$, LH $(-27.0 \pm 44.9 \%), \mathrm{MH}(-23.8 \pm 38.9 \%), \mathrm{M} 4-5(-22.7 \pm$ $33.4 \%)$, hallux (-22 $\pm 65.0 \%)$, M1 (12.5 $\pm 29.8 \%)$, and M2-3 (-10.6 $\pm 31.7 \%)$ areas. RI values furthest from 1 were calculated under the hallux $(5.13 \pm 10.46)$, LH (4.73 \pm 10.48$), \mathrm{MH}$ (1.74 \pm 1.12$), \mathrm{M} 4-5$ (1.63 \pm 0.98$)$, 
Table 1.

Mean peak plantar pressure (PPP) values under eight footprint areas for nondisabled group and group with hemiparesis.

\begin{tabular}{|c|c|c|c|c|c|c|c|c|c|c|c|c|}
\hline \multirow[b]{2}{*}{ tion } & \multicolumn{6}{|c|}{ Nondisabled Group } & \multicolumn{6}{|c|}{ Group with Hemiparesis } \\
\hline & $\begin{array}{c}\text { PPP } \\
\text { CL } \\
(\mathrm{kPa})\end{array}$ & $\begin{array}{c}\text { PPP } \\
\text { PL } \\
(\mathbf{k P a})\end{array}$ & ES & $\begin{array}{c}\text { SI } \\
(\%)\end{array}$ & $\begin{array}{c}\text { IA } \\
(\%)\end{array}$ & RI & $\begin{array}{c}\text { PPP } \\
\text { UL } \\
(\mathbf{k P a})\end{array}$ & $\begin{array}{c}\text { PPP } \\
\text { AL } \\
\text { (kPa) }\end{array}$ & ES & $\begin{array}{c}\text { SI } \\
(\%)\end{array}$ & $\begin{array}{c}\text { IA } \\
(\%)\end{array}$ & RI \\
\hline MH & $296.6 \pm 61.3$ & $319.2 \pm 65.4^{*}$ & -0.36 & $-7.3 \pm 13.5$ & $-6.6 \pm 12.1$ & $0.94 \pm 0.13$ & $112.7 \pm 43.5$ & $81.7 \pm 40.5^{*}$ & 0.74 & $-32.6 \pm 58.6$ & $-23.8 \pm 38.9$ & $1.74 \pm 1.12$ \\
\hline $\mathrm{M}$ & $52.4 \pm 35.3$ & $52.0 \pm 32.5$ & 0.01 & $-3.3 \pm 50.1$ & $-3.0 \pm 36.9$ & $1.13 \pm 0.69$ & $36.8 \pm 16.2$ & $37 \pm 17.8$ & -0.01 & $-3.3 \pm 56.6$ & $-1.2 \pm 41.1$ & $1.25 \pm 0.81$ \\
\hline MM & $7.1 \pm 5.9$ & $5.1 \pm 3.5$ & 0.40 & $30.8 \pm 101.5$ & $17.1 \pm 58.4$ & $2.09 \pm 2.89$ & $7.3 \pm 5.7$ & $25.7 \pm 22.3^{\dagger}$ & -1.13 & $82.3 \pm 82.1$ & $49.0 \pm 49.8$ & $0.63 \pm 0.77$ \\
\hline M1 & $330.0 \pm 122$ & $311.8 \pm 96.4$ & 0.17 & $2.6 \pm 37.6$ & $2.3 \pm 29.3$ & $1.11 \pm 0.45$ & $121.6 \pm 25.2$ & $134.3 \pm 49.9^{*}$ & -0.61 & $14.5 \pm 41.1$ & $12.5 \pm 29.8$ & $0.96 \pm 0.54$ \\
\hline Hallux & $326.7 \pm 142.13$ & $363.6 \pm 161.7$ & -0.24 & $-10.4 \pm 31.0$ & $-8.9 \pm 24.8$ & $0.95 \pm 0.34$ & $53.5 \pm 46.5$ & $35.9 \pm 36.6$ & 0.42 & $-40.6 \pm 109.8$ & $8-22 \pm 65.0$ & $5.13 \pm 10.46$ \\
\hline \multicolumn{13}{|c|}{$\begin{array}{l}\text { Significant bilateral differences in PPP values verified by student's } \text { t-test and Wilcoxon test indicated by- } \\
{ }^{*} p<0.05 . \\
{ }^{\dagger} p<0.01 . \\
\text { AL = affected limb, CL = cushioning limb, ES = effect size, IA = index of asymmetry, } \mathrm{LH}=\text { lateral heel, } \mathrm{LM}=\text { lateral midfoot, } \mathrm{M}=\text { metatarsal (heads } 1-5 \text { ), } \mathrm{MH}= \\
\text { medial heel, } \mathrm{MM}=\text { medial midfoot, } \mathrm{PL}=\text { propulsive limb, } \mathrm{RI}=\text { ratio index, } \mathrm{SI}=\text { symmetry index. }\end{array}$} \\
\hline
\end{tabular}

Table 2.

Correlation coefficients of effect size (ES), symmetry index (SI), index of asymmetry (IA), and ratio index (RI) calculated for eight footprint areas for nondisabled group and group with hemiparesis.

\begin{tabular}{|c|c|c|c|c|c|c|c|c|}
\hline \multirow{2}{*}{ Statistic } & \multicolumn{4}{|c|}{ Nondisabled Group } & \multicolumn{4}{|c|}{ Group with Hemiparesis } \\
\hline & ES & SI & IA & $\mathbf{R I}$ & ES & SI & IA & RI \\
\hline ES & 1 & $0.90^{*}$ & $0.90^{*}$ & $0.81^{\dagger}$ & 1 & $-0.90^{*}$ & $-0.98^{\ddagger}$ & $0.81^{\dagger}$ \\
\hline SI & - & 1 & $1^{\ddagger}$ & $0.76^{\dagger}$ & - & 1 & $0.93^{\ddagger}$ & $-0.95^{*}$ \\
\hline IA & - & - & 1 & $0.76^{\dagger}$ & - & - & 1 & $0.83^{\dagger}$ \\
\hline RI & - & - & - & 1 & - & - & - & 1 \\
\hline
\end{tabular}

Significant correlation with $p<0.05$ level of confidence.

*Significant correlation with $p<0.01$ level of confidence.

${ }^{\ddagger}$ Significant correlation with $p<0.001$ level of confidence.

MM (0.63 \pm 0.77), LM (1.25 \pm 0.81$)$, and M2-3 (1.25 \pm 0.48 ) areas. Correlation coefficient values (Table 2 ) were significant for ES and SI ( $\left.p<0.01, R^{2}=0.81\right)$, ES and IA $\left(p<0.01, R^{2}=0.96\right)$, ES and RI $\left(p<0.05, R^{2}=0.67\right)$, SI and IA $\left(p<0.01, R^{2}=0.86\right)$, SI and RI $\left(p<0.05, R^{2}=\right.$ $0.90)$, and IA and RI $\left(p<0.05, R^{2}=0.69\right)$ (Table 2).

\section{Effect Size and Asymmetry Indexes Between Groups}

ES, SI, and IA absolute values were significantly higher in the group with hemiparesis than in the nondisabled group. ES values were $0.63 \pm 0.35$ for the nondisabled group versus $0.20 \pm 0.14$ for the group with hemiparesis. SI values were $32.77 \pm 24.49 \%$ for the group with hemiparesis versus $8.08 \pm 9.65 \%$ for the nondisabled group. IA values were $21.13 \pm 14.17 \%$ for the group with hemiparesis versus $5.74 \pm 5.33 \%$ for the nondisabled group. For all indexes, $p<0.05$.

\section{DISCUSSION}

We designed our study to compare the different methods for quantifying the asymmetry of normal and pathological asymmetric gait. Our strategy was to (1) verify whether the footprint locations associated with the greatest bilateral differences in PPP values were affected by the method of quantification used and (2) test the sensitivity of the ES statistic in distinguishing degrees of asymmetry. For SI, IA, and ES, the higher the difference from 0 , the higher the asymmetry between the bilateral parameters. For RI, the higher the difference was from 1, the higher the asymmetry.

\section{Asymmetry Quantification Analyses}

We found significant correlations between the ES, SI, IA, and RI values of the two groups, which demonstrates an agreement between the different quantification methods. For the nondisabled group, the same four areas with the 
greatest asymmetry are shown by ES, SI, and IA (MM, hallux, LH, and MH) (Table 1). The MM area appeared to be more asymmetric than the other footprints, whereas the $\mathrm{LH}, \mathrm{MH}$, and hallux areas appeared to have an almost identical degree of asymmetry. Nevertheless, three out of the four greatest asymmetric areas measured by RI were LM, M1, and M2-3. This result explains the lower statistical power of the correlation for RI and the other procedures $(p<0.05)$. Worth noting is that the greatest asymmetric area (MM for all the procedures), was not shown by the statistical test to be bilaterally different. For the group with hemiparesis, each area with an ES value higher than 0.5 was associated with a significant bilateral difference (LH, MH, MM, M4-5, and M1) (Table 1). In our study, ES seem to provide sufficient confidence in detecting asymmetry with moderate magnitude. Nevertheless, these results need to be interpreted with caution because of the sample size of the group with hemiparesis and the lack of step-by-step reliability. RI asymmetry quantifications were very different from ES, SI, and IA. RI highlighted that the hallux and LH areas were five times more asymmetrical than the other footprints (5.13 \pm 10.46 and $4.73 \pm 10.48$ for hallux and LH, respectively). This difference could be attributed to a denominator close to 0 , which considerably increased the RI values. Limitations of RI in interpreting the asymmetry in nondisabled gait have also been pointed out by Wall and Turnbull [32] and Sadeghi et al. [2].

\section{Index Interpretation}

In spite of presenting functional classifications of data, we found that the SDs for all classical indexes (SI, IA, and RI) were higher than their mean values, and debating such interindividual variability data is difficult. Moreover, values calculated from SI, IA, or RI never reflected perfect agreement between each limb (SI or IA $=0$ or RI = 1), which immediately implies asymmetry. Furthermore, the sizes of the differences have no statistical basis. Each investigator or reader of the research must determine the importance of the difference to interpret whether high asymmetry exists. The calculation of percentage does not consider the variance of bilateral differences in the parameters studied (i.e., PPP) and cannot, therefore, be accurately compared either within or across research studies. By including the variance in the calculation, the ES accounts for the variation within and across samples, making it standardized and even more accurate when descriptions of the asymmetries are investigated [24]. For instance, asymmetry magnitude between nondisabled groups and groups with hemiparesis with different sample sizes and variance could be compared in our study because of the normalized asymmetries in SDs.

The statistical limits proposed by Cohen seem to be relevant for the diagnosis of the magnitude of the differences in PPP values [25]. Indeed, ES values for the nondisabled group were not higher than 0.4 (a moderate difference). On the contrary, the group with hemiparesis showed ES values $>0.8$ (a large difference). However, to our knowledge, no study has used this method to evaluate the size of asymmetry in gait for a normal and a pathological population. As such, for the moment, proposing a new scale of statistical limits in gait may be inappropriate. For instance, in the strength training research of Rhea, a new scale was proposed based on over 3000 ES collected from 400 studies [24]. Producing a new scale was not the aim of our study; we rather sought to present and test the ES statistic in the plantar pressure asymmetry in gait, which has never been conducted before.

With our study, we conclude that moderate bilateral differences exist under the MM in nondisabled gait. The significant differences under the $\mathrm{LH}$ and $\mathrm{MH}$ could be considered small. This conclusion may be considered in the diagnosis of pathological gait under these footprint locations or to guide the rehabilitation process. For instance, moderate asymmetry (ES $>0.5$ ) has to be considered pathological for all the footprint locations except MM. Conversely, significant bilateral differences under LH and MH should not be diagnosed as pathological when they are categorized as small with ES (ES < 0.5). Moreover, the absolute ES size values may be more meaningful than the $p$-values, especially in cases where $p$ is close to significance [5] (for example, $p=0.09$ for MM for the nondisabled group, while ES values are $0.40 ; p=$ 0.1 for hallux for the group with hemiparesis, while ES values are 0.42 ). In such cases, information provided by the ES value may prevent the researcher from making a type II error by lack of statistical power because of a small sample size or large variance of the data [33].

\section{Sensitivity of Effect Size Statistic}

The greatest gait asymmetry for the group with hemiparesis was expressed by ES, SI, and IA values significantly furthest from 0 for each area, with the exception of LM (Table 1). This footprint location seemed not to be influenced by hemiparesis when we looked at the asymmetry in the PPP. In spite of the evidence for the greater asymmetry for the group with hemiparesis, RI is the only index that shows values closer to 1 for the group with hemiparesis when compared with the nondisabled group 
(see MM and M1 in Table 1), indicating a lack of reliability for this index. This lack of reliability is confirmed by the nonsignificant difference for this index between the nondisabled group and the group with hemiparesis. As mentioned previously, the size of the differences for SI, IA, and RI have no statistical basis. Limits between normal and pathological asymmetry of gait in the PPP distribution were different for each area. For instance, the SI value for the nondisabled group corresponding to "normal” for MM was $30.8 \pm 101.5$ percent, whereas the SI value for the group with hemiparesis corresponding to "pathological" for M4-5 was $-31.8 \pm 46.7$ percent. The values of SI could not be discussed without statistical references. Conversely, ES allows us to normalize the measurement of the magnitude of the asymmetry. All footprint areas for the group with hemiparesis increased the significance of the asymmetry according to the Cohen classification except for LH and M2-3 (ES = 0.01 and 0.13 for the nondisabled group and ES $=-0.01$ and 0.35 for the group with hemiparesis for LM and M2-3, respectively) [25]. Therefore, ES appears to be reliable for detecting asymmetry of gait in normal and pathological PPP values.

\section{CONCLUSIONS}

We investigated the usefulness of the ES statistic in detecting plantar pressure asymmetry by comparing subjects presenting marked gait asymmetries with subjects who seem to have "normal” gait patterning. Our results could serve as a reference in the PPP distribution for one to discriminate normal versus abnormal gait asymmetry. Comparisons between ES and standard asymmetry quantification procedures (SI, IA, and RI) demonstrated that ES is simpler and more reliable for interpreting normal and pathological gait. Further studies on asymmetry of gait using ES are needed to shed further light on complete information about significant bilateral differences.

\section{ACKNOWLEDGMENTS}

This material is the result of work supported in part with resources from the Conseil Régional Nord-Pas de Calais, the Délégation Régionale à la Recherche et à la Technologie du CHRU of Lille, and the Institut Régional de Recherche sur le Handicap, France.

The authors have declared that no competing interests exist.

\section{REFERENCES}

1. Herzog W, Nigg BM, Read LJ, Olsson E. Asymmetries in ground reaction force patterns in normal human gait. Med Sci Sports Exerc. 1989;21(1):110-14. [PMID: 2927295$]$

2. Sadeghi H, Allard P, Prince F, Labelle H. Symmetry and limb dominance in able-bodied gait: A review. Gait Posture. 2000;12(1):34-45. [PMID: 10996295]

3. Gundersen LA, Valle DR, Barr AE, Danoff JV, Stanhope SJ, Snyder-Mackler L. Bilateral analysis of the knee and ankle during gait: An examination of the relationship between lateral dominance and symmetry. Phys Ther. 1989; 69(8):640-50. [PMID: 2748719]

4. Sadeghi H, Allard P, Duhaime M. Functional gait asymmetry in able-bodied subjects. Hum Mov Sci. 1997;16(2): 243-58.

5. Vincent WJ. Statistics in kinesiology. 2nd ed. Champaign (IL): Human Kinetics; 1999.

6. Femery VG, Moretto PG, Hespel JM, Thevenon A, Lensel G. A real-time plantar pressure feedback device for foot unloading. Arch Phys Med Rehabil. 2004;85(10):1724-28. [PMID: 15468038]

7. Chao EY, Laughman RK, Schneider E, Stauffer RN. Normative data of knee joint motion and ground reaction forces in adult level walking. J Biomech. 1983;16(3):219-33. [PMID: 6863337]

8. Robinson RO, Herzog W, Nigg BM. Use of force platform variables to quantify the effects of chiropractic manipulation on gait symmetry. J Manipulative Physiol Ther. 1987; 10(4):172-76. [PMID: 2958572]

9. Vagenas G, Hoshizaki B. A multivariable analysis of lower extremity kinematic asymmetry in running. Int J Sports Biomech. 1992;8(1):11-29.

10. Ganguli S, Mukherji P, Bose KS. Gait evaluation of unilateral below-knee amputees fitted with patellar-tendon-bearing prostheses. J Indian Med Assoc. 1974;63(8):256-59. [PMID: 4443595]

11. Seliktar R, Mizrahi J. Some gait characteristics of belowknee amputees and their reflection on the ground reaction forces. Eng Med. 1986;15(1):27-34. [PMID: 3699235]

12. Andres RO, Stimmel SK. Prosthetic alignment effects on gait symmetry: A case study. Clin Biomech. 1990;5:88-96.

13. Femery VG, Moretto PG, Renaut H, Thevenon A, Lensel G. Measurement of plantar pressure distribution in hemiplegic children: Changes to adaptative gait patterns in accordance with deficiency. Clin Biomech (Bristol, Avon). 2002;17(5):406-13. [PMID: 12084546]

14. Femery V, Moretto P, Renaut H, Thevenon A, Lensel G. Analyse des asymétries baropodométriques lors de la marche chez le sujet valide: Application à l'étude des asymétries chez l'enfant infirme moteur cérébral. Ann Réadaptation Méd Phys. 2002;45:114-22. 
15. Meyring S, Diehl RR, Milani TL, Hennig EM, Berlit P. Dynamic plantar pressure distribution measurements in hemiparetic patients. Clin Biomech (Bristol, Avon). 1997; 12(1):60-65. [PMID: 11415673]

16. Hirasawa Y. An observation on standing ability of Japanese males and females. J Anthrop Soc Nippon. 1979;87:81-92.

17. Ounpuu S, Winter DA. Bilateral electromyographical analysis of the lower limbs during walking in normal adults. Electroencephalogr Clin Neurophysiol. 1989;72(5): 429-38. [PMID: 2469567]

18. Wheelright EF, Minns RA, Law HT, Elton RA. Temporal and spatial parameters of gait in children. I. Normal control data. Dev Med Child Neurol. 1993;35(2):102-13. [PMID: 8444324]

19. Matsusaka N, Fujitta M, Hamamina A, Norimatsu T, Suzuki R. Relationship between right and left leg in human gait from a view point of balance control. In: Winter DA, Norman R, Wells R, Hayes K, Patla D, editors. Biomechanics IX-A. Champaign (IL): Human Kinetics; 1985. p. 427-30.

20. Viel E, Perelle A, Peyranne J, Esnault M. Analyse tridimensionnelle de la marche et de l'appui au sol, Mesure des mouvements du bassin et des segments squelettiques du membre inférieur; importance des contraintes supportées par le pied au sol. Méd Chir Pied. 1985;2:151-60.

21. Hirokawa S. Normal gait characteristics under temporal and distance constraints. J Biomed Eng. 1989;11(6):449-56. [PMID: 2811343]

22. Laassel EM, Loslever P, Voisin PH, Herlant M. Analyse multidimensionnelle des forces de réaction du pied au cours de la marche normale. Acta Orthopoedica Belgica. 1992;58(3):272-79.

23. Zmitrewicz RJ, Neptune RR, Walden JG, Rogers WE, Bosker GW. The effect of foot and ankle prosthetic components on braking and propulsive impulses during transtibial amputee gait. Arch Phys Med Rehabil. 2006;87(10):1334-39. [PMID: 17023242]

24. Rhea MR. Determining the magnitude of treatment effects in strength training research through the use of the effect size. J Strength Cond Res. 2004;18(4):918-20. [PMID: 15574101]

25. Cohen J. Statistical power analysis for the behavioral sciences. Hillsdale (NJ): Lawrence Erlbaum; 1988.

26. Goble DJ, Marino GW, Potvin JR. The influence of horizontal velocity on interlimb symmetry in normal walking. Hum Mov Sci. 2003;22(3):271-83. [PMID: 12967758$]$

27. Schaff PS. An overview of foot pressure measurement systems. Clin Podiatr Med Surg. 1993;10(3):403-15. [PMID: 8364844]

28. Cavanagh PR, Hewitt FG Jr, Perry JE. In-shoe plantar pressure measurement: A review. Foot. 1992;2:185-94.

29. Chesnin KJ, Selby-Silverstein L, Besser MP. Comparison of an in-shoe pressure measurement device to a force plate: Concurrent validity of center of pressure measurements. Gait Posture. 2000;12(2):128-33. [PMID: 10998609]

30. Shrout PE, Fleiss JL. Intraclass correlation: Uses in assessing rater reliability. Psychol Bull. 1979;86:420-28.

31. Thomas JR, Nelson JK. Research methods in physical activity. 4th ed. Champaign (IL): Human Kinetics; 2001.

32. Wall JC, Turnbull GI. Gait asymmetries in residual hemiplegia. Arch Phys Med Rehabil. 1986;67(8):550-53. [PMID: 3741082]

33. Mullineaux DR, Bartlett RM, Bennett S. Research design and statistics in biomechanics and motor control. J Sports Sci. 2001;19(10):739-60. [PMID: 11561672]

Submitted for publication July 5, 2006. Accepted in revised form January 29, 2007. 